\title{
METODOLOGIAS INOVADORAS COMO POSSIBILIDADE EFETIVA DE APRENDIZAGEM PARA O CONTEXTO PÓS-PANDÊMICO
}

\author{
Fabíola Cadete Silva ${ }^{1}$ \\ Petronilha Morais Moreira Pereira ${ }^{2}$ \\ Rogério Leal de Sousa ${ }^{3}$ \\ Tarcísio Welvis Gomes de Araújo ${ }^{4}$ \\ Thayane Nascimento Freitas ${ }^{5}$ \\ Ilka Márcia Ribeiro de Souza Serra ${ }^{6}$
}

\section{RESUMO}

Pensar, proativamente, a educação para o contexto pós-pandêmico incide em um exercício necessário de readequação às exigências e lacunas apresentadas pelo ensino remoto tal qual configurado em muitas realidades das escolas brasileiras. Diante da veracidade desse pressuposto, esta pesquisa objetivou reconhecer as metodologias inovadoras e o uso das novas Tecnologias Digitais (TDs) como possibilidade de desenvolvimento das competências tecnopedagógicas docentes para o contexto educacional na pós- pandemia. Optou-se, neste trajeto investigativo, pela pesquisa descritiva, utilizando, como instrumento para a produção dos dados, um questionário on-line, o qual contou com a participação de 13 (treze) professores das 3 (três) etapas da educação básica da rede pública do estado do Maranhão em efetivo exercício. Como lócus de investigação, foram escolhidos os municípios de Olinda Nova do Maranhão, Pedro do Rosário, São Luís e Timon. Para tratamento e interpretação dos dados coletados, optou-se pela análise do conteúdo. Como resultados obtidos na pesquisa, observou-se que a maioria dos entrevistados não utilizava tecnologias digitais em suas salas de aula antes do cenário pandêmico, demonstrando, ainda, um predomínio de habilidades básicas no uso das tecnologias. Ademais, apesar das dificuldades oriundas da ineficiência do letramento digital e dos recorrentes casos de exclusão digital, os educadores evidenciaram que estão fazendo uso de algumas

\footnotetext{
${ }^{1}$ Mestrado em Educação Inclusiva em Rede pela Universidade Estadual do Maranhão. E-mail: fabycadete@ gmail.com

${ }^{2}$ Mestrado em Educação Inclusiva em Rede pela Universidade Estadual do Maranhão. E-mail: pm.asp@ hotmail.com

3 Mestrado em Educação Inclusiva em Rede pela Universidade Estadual do Maranhão. E-mail: rogeriolealsousa@gmail.com

${ }^{4}$ Mestrado em Educação Inclusiva em Rede pela Universidade Estadual do Maranhão. E-mail: twgaraujo@ gmail.com

${ }^{5}$ Mestrado em Educação Inclusiva em Rede pela Universidade Estadual do Maranhão. E-mail: thayanny_ freitas@hotmail.com

${ }^{6}$ Mestrado em Fitossanidade e Doutorado pela Universidade Federal Rural de Pernambuco. E-mail: ilka. serra@uema.br
} 
tecnologias digitais, plataformas e/ou aplicativos na mediação pedagógica e compreendem que as metodologias ativas são um importante aliado no aproveitamento do tempo e espaço escolar para o contexto pós-pandêmico.

Palavras-chave: Ensino Remoto. Metodologias Inovadoras. Competências Digitais.

\title{
INNOVATIVE METHODOLOGIES AS AN EFFECTIVE POSSIBILITY OF LEARNING FOR THE POST-PANDEMIC CONTEXT
}

\begin{abstract}
Thinking about education for the post-pandemic context in a proactive way involves a necessary exercise of readjustment to the demands and gaps presented by remote learning, as it is the case of many realities of Brazilian schools. Recognizing the veracity of this assumption, this research aimed to recognize innovative methodologies and the use of new digital technologies as a possibility for developing teaching techno-pedagogical skills for the educational context in the (post) pandemic. In this investigative path, we opted for descriptive research, using an online questionnaire as an instrument for the production of data, in which 13 (thirteen) teachers from the 3 (three) stages of the basic education from Maranhão's public system participated. For the investigation, the following municipalities were chosen: Olinda Nova do Maranhão, Pedro do Rosário, São Luís, and Timon. For the treatment and interpretation of the collected data, we opted for content analysis. With the results obtained in the survey, it was observed that the majority of respondents did not use digital technologies in their classroom before the pandemic scenario, demonstrating, also, a predominance of basic skills in the use of technologies. Despite the difficulties arising from the inefficiency of digital literacy and the recurring cases of digital exclusion, the teachers showed that they are making use of some digital technologies, platforms and/or applications in pedagogical mediation, and they understand active methodologies as an important ally in the use of school time and space for the post-pandemic context.
\end{abstract}

Keywords: Remote Learning. Innovative Methodologies. Digital skills.

\section{METODOLOGÍAS INNOVADORAS COMO POSIBILIDAD EFECTIVA DE APRENDIZAJE PARA EL CONTEXTO POST-PANDÉMICO}

\section{RESUMEN}

Pensar proactivamente la educación para el contexto pospandémico se centra en un necesario ejercicio de reajuste a las demandas y brechas que presenta la educación a 
distancia configurada en muchas realidades de las escuelas brasileñas. Reconociendo la veracidad de este supuesto, esta investigación tuvo como objetivo reconocer las metodologías innovadoras y el uso de las nuevas tecnologías digitales como una posibilidad para el desarrollo de habilidades didácticas técnico-pedagógicas para el contexto educativo en la (pos) pandemia. En este camino investigativo se optó por la investigación descriptiva, utilizando un cuestionario en línea como instrumento de producción de datos, en el que participaron 13 (trece) docentes de las 3 (tres) etapas de la Educación Básica de la red. Estado de Maranhão, en ejercicio efectivo. Como lugar de investigación se eligieron las ciudades de Olinda Nova do Maranhão, Pedro do Rosário, São Luís y Timon. Para el tratamiento e interpretación de los datos recogidos, optamos por el Análisis de Contenido. Con los resultados obtenidos en la encuesta, se observó que la mayoría de los encuestados no utilizaba tecnologías digitales en el aula ante el escenario pandémico, demostrando también un predominio de habilidades básicas en el uso de tecnologías. Apesar de las dificultades derivadas de la ineficiencia de la alfabetización digital y los casos recurrentes de exclusión digital, los docentes demostraron que están haciendo uso de algunas tecnologías, plataformas y / o aplicaciones digitales en la mediación pedagógica, y entienden las metodologías activas como un aliado importante en el uso desde el tiempo y el espacio escolar hasta el contexto pospandémico.

Palabras clave: Aprendizaje remoto. Metodologías inovadoras. Habilidades digitales.

\section{INTRODUÇÃO}

A pandemia do novo coronavírus impôs ao mundo mudanças em todos os aspectos da sociedade. A necessidade de manter o distanciamento físico, como medida de contenção do contágio da Covid-19, é levada ao contexto educacional, e, com ela, as práticas educativas, em suas mais variadas modalidades, seguem afetadas pela necessidade de reconfiguração dos novos tempos e espaços de acesso aos saberes sistematizados.

Com isso, a urgência no que concerne à reconfiguração da práxis pedagógica, bem como a garantia de meios que favorecessem a continuidade da educação escolar, foram medidas emergenciais que fizeram e fazem parte da vida de gestores escolares, docentes e discentes. Nesse tocante, as aulas e atividades letivas presenciais foram transportadas ao cenário das plataformas digitais e, em não raros os casos, aos velhos métodos e formas bancárias de se conceber e fazer educação.

Como consequência dessa migração de espaços, sem mudanças de posturas, plataformas de estudos acabam se transformando em repositórios de conteúdos, o que evidencia a exigência de absorver o que está sendo colocado nesses ambientes, para, somente depois, 
devolver o aprendido em forma de avaliações e atividades pontuais. As aulas síncronas tornam-se um espaço privilegiado de transmissão e cobrança de prazos. Assim, as reflexões se materializam quando afirmam que, "por si só, a tecnologia não garante aprendizagem, tampouco supera velhos paradigmas”. (BASEIO; SANTOS; CARNEIRO, 2021, p.5).

Enveredando-se por essa vertente e acreditando na visão de Moreira, Henriques e Barros (2020), percebe-se a necessidade de substituir esse ensino remoto de emergência, importante em uma primeira fase, por uma educação digital em rede, de qualidade. Sabe-se, para tanto, que os desafios são inúmeros, dado o longo período de afastamento das aulas presenciais e a limitação de acesso aos recursos tecnológicos por muitos docentes e discentes.

No entanto, a visão proativa e otimista de pensar o ensino numa perspectiva pós-pandêmica conduziu à reflexão acerca das metodologias inovadoras e o uso das Tecnologias Digitais (TDs), sugerindo-as não como solução na resolução dos atuais problemas educacionais, mas como possibilidade metodológica de reconfiguração do ensino e da prática docente, no sentido de melhor aproveitamento do espaço/tempo de aprendizagem.

A partir disso, levando em consideração as ideias de Moran (2015), Dias Trindade e Moreira (2018) e, ainda, as percepções de professores de alguns municípios do estado do Maranhão, buscou-se compreender de que forma as novas tecnologias têm auxiliado as ações pedagógicas no atual modelo de ensino e quais os limites e possibilidades na utilização das metodologias ativas, por intermédio ou não de TDs, enquanto proposta efetiva no desenvolvimento e construção de aprendizagem.

$\mathrm{Na}$ tentativa de encontrar respostas a essas questões, as discussões aqui propostas foram estruturadas em cinco seções. A primeira seção, intitulada "Competências docentes na era das Tecnologias Digitais (TDs)", faz uma breve abordagem sobre o conceito de competências e traz, à luz de modelos espanhóis, referenciais para o entendimento de habilidades e conhecimentos necessários no processo de formação de sujeitos competentes no que tange à tecnologia. A segunda seção, "Formação docente e as TDs como possibilidade de intervenção pedagógica”, propicia a discussão sobre a necessidade de formações docentes com reais aplicabilidades no contexto de sala de aula, sugerindo como proposta o modelo TPCK.

Aterceira seção versa sobre as "Metodologias ativas e as possibilidades efetivas de aprendizagem em contexto educacional pós-pandêmico", trazendo uma reflexão, conforme Moran (2015), sobre a definição e o uso das metodologias ativas como possibilidade efetiva de aprendizagem e reconfiguração do ensino em um ecossistema educacional sustentável. A seção "Metodologia" apresenta os procedimentos que conduziram as investigações e a escuta das percepções docentes acerca do ensino remoto e das TDs.

Por último, abordam-se as experiências docentes que se referem aos êxitos e desafios encontrados no atual modelo de ensino vigente, um espaço de reflexão sobre o 
ensino remoto à luz daqueles que vivenciam os limites e possibilidades expostas nesta trajetória.

Pretende-se, portanto, mediante as discussões fomentadas, apresentar as metodologias inovadoras e o uso das novas TDs como possibilidade de desenvolvimento das competências tecnopedagógicas docentes no contexto da educação na pós-pandemia, pois se acredita que a formação de sujeitos ativos e competentes para atuação na atual sociedade perpassa a desconstrução e rompimento com paradigmas centralizadores de ensino.

\section{COMPETÊNCIAS DOCENTES NA ERA DAS TECNOLOGIAS DIGITAIS (TDS)}

Na dinâmica coloquial das relações linguísticas, é constante o emprego da palavra competência como sinônimo de responsabilidade. Em variados contextos pedagógicos, a mesma é compreendida como mecanismo que exige a presença ou não de habilidades no desempenho e resolução das demandas concretas da realidade. Ou seja, competência é vista, numa esfera cognitiva, enquanto habilidade que incide na capacidade de pôr em prática o conhecimento adquirido.

No dicionário on-line de Língua Portuguesa, ela é definida como "capacidade decorrente de profundo conhecimento que alguém tem sobre um assunto" (7GRAU, 2021). Assim, pode-se afirmar que é a aptidão que o sujeito apresenta em adequar-se aos contextos que vivencia.

Para Perrenoud e Magne (1999, p. 7), define competência como a "capacidade de agir eficazmente em um determinado tipo de situação, apoiada em conhecimentos, mas sem limitar-se a eles".

Nesse mosaico de conceitos, as competências não podem ser vistas, simplesmente, como sinônimo de conhecimento, embora estejam fortemente interligadas a este. É importante, também, mobilizar a capacidade de agir de maneira satisfatória na resolução de problemas diversos, já que "as competências que manifestamos através de nossas ações não são baseadas apenas em saberes, mas são a integração, utilização ou mobilização de conhecimentos." (PERRENOUD; MAGNE, 1999, p. 7).

Em consonância com a visão de Perrenoud e Magne (1999), a Base Nacional Curricular Comum (BNCC), documento que norteia aprendizagens a serem asseguradas na formação dos alunos na etapa da educação básica, destaca que as competências se referem à mobilização de conhecimentos, atitudes, valores e habilidades que devem fundamentar princípios orientadores de uma educação que atenda às demandas formativas da multifacetada e plural sociedade brasileira.

A concepção proposta no documento fundamenta o conceito para além das definições reducionistas que põem a mera aquisição de conhecimentos como competências adquiridas, manifestando a mobilização de habilidades na resolução de demandas reais. 
Dessa forma, apresentar competência é integrar conhecimentos diversos, desde científicos a cotidianos, envolvendo os saberes metodológicos e técnicos, a fim de resolver situações ou problemas no âmbito da atividade laboral (TANGUY, 1997). Essa prática se mostra como exercício desafiador para o docente, na medida em que ele precisa ter, em seu arcabouço pedagógico, saberes que assegurem ação significativa no processo de ensino-aprendizagem.

Dessarte, reconhecendo o contexto atual de restrição à interação nos espaços físicos e geográficos, o uso das tecnologias tem sido, dia após dia, estimulado no processo educacional. Apesar das mesmas estarem presentes há muito tempo, é neste período que o digital toma espaço em todas as modalidades da educação e traz consigo a necessidade do uso das plataformas digitais, revelando a integração favorável ao processo educativo entre as competências pedagógica e digital. Contudo, o uso de tecnologias não apresentará efeitos favoráveis se as mesmas não manifestarem sustentação pedagógica, pois a tecnologia deve responder ao propósito para o qual é usada.

Sendo assim, as tecnologias disponíveis não são o foco, mas como o professorado pode usá-las pedagógica e didaticamente, isto é, com o objetivo de exponenciar o saber e integrar o aluno à cooperação e construção de conhecimentos, aumentando, assim, o desafio imposto ao educador, já que o letramento digital é uma realidade no cotidiano de crianças, jovens e adultos. A imersão em uma sociedade digital, envolta na volatilidade das informações e no amplo acesso à produção e à divulgação do conhecimento, favorece o surgimento de indagações pertinentes, dentre as quais, destacam-se: Quais seriam as competências docentes necessárias para o atendimento dos direitos de aprendizagem e para a formação de alunos tecnocompetentes que atuem de forma proativa em sua realidade?

$\mathrm{Na}$ tentativa de responder a esse questionamento, ilustra-se a realidade da Espanha, país europeu, enquanto um exemplo a ser seguido, na formação de sujeitos tecnologicamente competentes para atuação criativa em sua realidade. Suas políticas públicas promovem a formação sobre competências digitais, em que se toma por base a correlação entre competências, conteúdos e critérios de avaliação para a educação primária e secundária, seguindo, desse modo, as recomendações da União Europeia e da Organização das Nações Unidas para a Educação, a Ciência e a Cultura (UNESCO).

Com efeito, a finalidade é proporcionar ao cidadão o pleno desenvolvimento pessoal, social e profissional, interligando-o efetivamente às exigências da globalização, corroborando, assim, com o desenvolvimento econômico ligado ao saber (SILVA; BEHAR, 2019).

Contextualizando a realidade brasileira, o professor tem sido, constantemente, cobrado a apresentar competências digitais condizentes com as demandas impostas pelo cenário pandêmico, devendo, pois, tornar seu ambiente virtual um espaço de participação 
e colaboração que estimule a curiosidade e o protagonismo dos discentes. A competência digital presente na formação docente da Espanha permite que o educador tenha acesso à informação, à comunicação e, também, facilidade na criação e disseminação de conteúdo.

O aprimoramento das capacidades de uso das Tecnologias Digitais (TDs) circunda, assim, o aperfeiçoamento de habilidades associadas ao acesso à informação, à organização, ao uso da comunicação, à formação de conteúdo e às respostas para os problemas, tanto em contextos formais quanto em informais. O indivíduo precisa ser capaz de utilizar corretamente os meios tecnológicos que lhe são proporcionados, fundamentandose em ações e valores que elucidem problemas reais de forma eficiente, avaliando e selecionando novas fontes de informação e inovações em função da sua utilidade, para realizar tarefas ou objetivos específicos.

Posto isso, resgata-se a visão de Dias Trindade e Moreira (2018), por acreditar, como eles, que a integração de pedagogias inovadoras, tecnologias e conteúdos digitais é um ambiente profícuo para o avanço no ensino-aprendizagem. Os professores, para tanto, devem ter preparo no uso dessas tecnologias, a fim de as manipularem para a criação de novos ambientes de aprendizagem, promovendo competências necessárias para sua autoformação e formação dos seus educandos.

De acordo com Figueiredo (2016, p. 20) diz que:

O desafio não é [...] o de integrar o "digital" na relação ensino aprendizagem, nem de desenvolver nas jovens competências instrumentais para o "uso" das tecnologias da informação e da comunicação, mas sim o de os preparar para uma pertença cultural plena, madura e ativa na nova era.

Nestes novos espaços de convivência ou ecossistemas de aprendizagem, a tecnologia pode assumir-se como uma ferramenta que contribui para a resolução das lacunas existentes, por meio, em uma primeira categoria, da preparação, da materialização e da verificação das aprendizagens e, em seguida, da aquisição de resultados por meio do desenvolvimento do capital humano e da consolidação dos sistemas de gestão.

\subsection{Formação Docente e as TDS como possibilidade de intervenção pedagógica}

O atual modelo de ensino vigente, pautado no afastamento do espaço físico escolar, em função da medida preventiva contra a Covid-197 , tem gerado incertezas e reflexões significativas quanto ao uso das TDs e as possibilidades efetivas de aprendizagem. Expressões como "atividades remotas", "ensino híbrido", "aulas síncronas e assíncronas" adentram no âmbito das relações institucionais e exigem da escola, dos alunos e de seus familiares uma nova postura que contemple as atuais peculiaridades.

\footnotetext{
${ }^{7}$ A Covid-19 é uma doença causada pelo coronavírus denominado SARS-CoV-2, que apresenta um espectro clínico variando de infecções assintomáticas a quadros graves (BRASIL, 2020).
} 
Ao mesmo tempo, essa transformação repentina tem gerado dúvidas e inseguranças, principalmente, sobre o que se esperar da educação no contexto póspandêmico, dados os longos meses regidos por uma medida paliativa de ensino que, indiscriminadamente, tem mostrado suas fragilidades.

Esse modelo adotado no Brasil e no mundo, denominado Ensino Remoto Emergencial (ERE), consiste, segundo Behar (2020), em uma modalidade que pressupõe o distanciamento geográfico de professores e alunos e foi adotado de forma temporária nas diferentes etapas de escolarização por instituições educacionais do mundo inteiro.

O ERE está assegurado pelo Parecer do Conselho Nacional de Educação/CP $\mathrm{n}^{\circ}$ 05/2020, aprovado no dia 28 de abril de 2020, que trouxe diretrizes para orientar as escolas da educação básica e as instituições de ensino superior, com o intuito de norteá-las para o atendimento ao direito dos estudantes em todo o território nacional, resguardando os direitos e objetivos de aprendizagem para cada etapa educacional, de acordo com a BNCC (BRASIL, 2020). Para tanto, entre outros documentos normativos, foi emitida, também, a Portaria $n^{\circ}$ $343 / 2020$, que estabelece a mudança das aulas presenciais para aulas em meios digitais.

Partindo do pressuposto de inserção das TDs como um dos recursos principais na orientação do ensino remoto, compreende-se que, ao mesmo tempo em que elas se desenham como possibilidade de exploração e mediação das aprendizagens, podem se converter em antagonistas no processo. Ou seja, existem contextos em que os alunos não dispõem de recursos tecnológicos, o que dificulta os vínculos institucionais e limita a capacidade criativa de pesquisar e agir sobre seu conhecimento.

Por outro lado, o fato de contar com o apoio desse recurso não significa, necessariamente, uma mediação pedagógica de qualidade, visto que, como afirmam Moreira, Henriques e Barros (2020, p. 352), "na maioria dos casos as tecnologias estão sendo utilizadas numa perspectiva meramente instrumental, reduzindo as metodologias e as práticas a um ensino apenas transmissivo".

Acredita-se na importância de considerar a "qualidade do uso das tecnologias nos contextos educativos, uma vez que ela deve ultrapassar a mera instrumentalização do mundo, possibilitando melhor compreensão do poder e do papel dos veículos de informação e comunicação". (GOERDET; ARNDT, 2020, p. 61).

A utilização desses meios, para fins educativos que viabilizem condições efetivas de intervenções pedagógicas, pressupõe a formação e o aperfeiçoamento constante da prática docente; para tal, é necessário que o professor, sempre que possível, faça uma avaliação da sua competência digital, no intuito de utilizar as TDs de forma adequada em suas práticas. (DIAS-TRINDADE, MOREIRA, 2018; DIAS-TRINDADE, SANTOS, 2021).

Portanto, para implementar as Tecnologias da Informação e Comunicação (TICs) a serviço de fins educacionais eficientes e aplicáveis, as ações de orientações 
metodológicas devem estar pautadas em formações específicas, de maneira que não haja equívocos quanto ao seu uso e aplicabilidade, pois, segundo Teodoro e Freitas (1992), esse processo não pode ser visto apenas como uma mera transição tecnológica, por meio da substituição do tradicional quadro negro ou do livro pelo computador.

Para Coutinho (2011), essa mudança deve ser encarada como uma alteração no modo como se aprende, nas formas de interação entre quem aprende e quem ensina e até na visão de como se reflete sobre a natureza do conhecimento. Nesse sentido, a sua inserção no contexto escolar deve contar com mediações pedagógicas que contribuam nos processos de construções colaborativas para estímulo e formação ativa de sujeitos críticos, criativos e proativos.

Na perspectiva de formações que atendam e orientem, especificamente, o uso das tecnologias, para fins de enriquecimento das possibilidades de construção de conhecimento, sugere o modelo TPCK (Technological Pedagogical Content Knowledge). Esse conceito incide na interseção entre três tipos de conhecimentos necessários para o professor, a saber: "[...] a capacidade de ensinar um determinado conteúdo curricular; [...] saber selecionar os recursos tecnológicos mais adequados; [...] saber usar esses recursos no processo de ensino e aprendizagem". (MISHRA; KOEHLER, 2006, p. 10 apud COUTINHO, 2011, p. 16).

A abordagem TPCK, conforme o autor, corresponde a um conhecimento de conceitos e técnicas que usam a tecnologia para fins intencionais de construção de aprendizagem, o que presume uma mudança de postura docente, na qual práticas centralizadoras e verticalizadas de ensino são substituídas por espaços colaborativos de construções pelo intermédio, inclusive, das "mediações pedagógicas".

De acordo com Masetto (2000, p.144), a mediação pedagógica pode ser entendida "como a atitude, o comportamento do professor que se coloca como um facilitador, incentivador ou motivador da aprendizagem, sendo, portanto, uma ponte entre o aprendiz e sua aprendizagem".

Todos os profissionais envolvidos no processo de ensino-aprendizagem devem estar igualmente capacitados para o uso das Tecnologias Digitais da Informação e Comunicação (TDICs), pois a mediação pedagógica, mediante as tecnologias, requer dos professores um exercício intenso de autonomia na organização do tempo-espaço de ensino, adaptando e/ou produzindo novos artefatos para uso individual ou de forma colaborativa.

Nessa proposta facilitadora de ensino, o aluno assume o papel de aprendiz ativo e participante (não mais passivo e repetidor), de sujeito de ações levado a aprender e a mudar seu comportamento, imperando, portanto, o conceito de autoaprendizagem, processo em que o aluno aprende sozinho, e o de interaprendizagem, onde o aluno aprende com o professor e com os seus colegas (MASETTO, 2000). 
Diante do exposto, acredita-se que, assim como Moreira e Schlemmer (2020), utilizar as mesmas metodologias e práticas pedagógicas presenciais nos ambientes digitais on-line não constitui uma prática muito eficaz. E, para ressignificar essa proposta, faz-se necessário investir em formações de qualidade, que estejam pautadas em orientações com aplicabilidades claras de uso das tecnologias para fins intencionais e enriquecedores dos processos de aprendizagem.

Os autores acrescentam, ademais, que isso implicará mudanças na postura docente e viabilizará um ensino de maior qualidade para o desenvolvimento de competências que melhor contemplem as exigências do atual contexto de hiperconexão.

\section{METODOLOGIAS ATIVAS E AS POSSIBILIDADES EFETIVAS DE APRENDIZAGEM PARA O CONTEXTO EDUCACIONAL PÓS-PANDÊMICO}

Em estreita relação com as temáticas anteriores, encontra-se a concepção das metodologias inovadoras e da aprendizagem ativa. Aprendizagem ativa não deve estar relacionada às competências que perpassam abordagens tecnicistas, mas se refere às competências transversais numa perspectiva de que se aprende com pessoas, com objetos, com ferramentas, com mídias, entre outras formas.

No âmbito escolar, faz-se mister pensar em metodologias que permitam a atuação e a interação do aluno com seu objeto de conhecimento, ou seja, o modelo transmissivo, manejado, manipulado não contribui para as atuais exigências e, sobretudo, para a formação de sujeitos crítico-reflexivos e proativos, tão almejada no presente contexto socioeducacional.

A aula deve ser, diante desse pressuposto, um espaço que favoreça e estimule a discussão, existindo em uma realidade contextualizada, num processo histórico em movimento. Além disso, precisa ser viva, funcionando como dupla direção: de receber a realidade para trabalhá-la cientificamente e a de voltar para ela de forma atualizada, com propostas novas de intervenção. (MASETTO, 2014).

Acredita-se, como Ferrarine, Saheb e Torres (2019, p. 5), "aprender de forma ativa envolve a atitude e a capacidade mental do aluno buscar processar, entender, elaborar e anunciar de modo personalizado o que aprendeu, muito diferente da atitude passiva de apenas ouvir e repetir modelos prontos".

Diante da citação acima, compreende-se que as metodologias ativas podem ser vistas como possibilidades enriquecedoras no desenvolvimento de competências que contemplem as atuais exigências do mundo das tecnologias digitais. No entanto, parte-se do pressuposto de que metodologias ativas não podem ser confundidas com TDs.

Embora possam ser consideradas como algo inovador, as metodologias ativas já refletiam as concepções de antigos estudiosos, como Sócrates, Paulo Freire e Vygotsky. 
Dessa forma, as mesmas podem ser consideradas como uma inovação incrementada, porque há melhorias significativas na sua utilização, inclusive, com o auxílio das TDICs. (SANTOS, 2020 apud BASEIO, SANTOS e CARNEIRO, 2021).

Corroborando esse pensamento, Moran(2018) traz um importante posicionamento que orienta, até mesmo, a proposta para um planejamento do ensino na perspectiva póspandêmica. Em sua visão, as metodologias ativas são estratégias de intervenção, que estão centradas na participação efetiva dos estudantes e na construção do processo de aprendizagem, de forma flexível, interligada e híbrida.

Torna-se importante enfatizar, por conseguinte, que existem diversas maneiras de explorar ativamente as potencialidades dos alunos que independem do uso das TDICs. Entre elas, cita-se a aprendizagem baseada em projetos, que é pautada na exploração de temas reais do contexto do discente, viabilizando, dessa forma, um percurso de significação do aprendizado, e, também, o PBL (Problem-Based-Learning), cujo método consiste na busca sistematizada de soluções à resolução de problemas, preferencialmente, reais, em um determinado contexto. Essas refletem apenas algumas das inúmeras possibilidades de propiciar ao aluno o protagonismo no seu processo de aprender (FERRARINE; SAHEB; TORRES, 2019).

Em realidades nas quais o uso das TDICs, seja por aparelhos móveis ou computadores, tenha maior alcance, sugere-se as metodologias ativas pautadas no modelo de ensino híbrido ou blended. O ensino híbrido, sob a perspectiva de Horn, Staker e Christensen (2015, p. 7), é entendido como um programa de educação formal, em que o aluno aprende, "pelo menos uma parte, por meio do ensino online, com algum elemento de controle do estudante sobre o tempo, lugar, modo e/ou ritmo do estudo, e pelo menos em parte em uma localidade física supervisionada".

Para Moran (2015), a educação formal é, cada vez mais, blended, misturada, híbrida, porque não acontece só no ambiente físico da sala de aula, mas nos múltiplos espaços do cotidiano que incluem os digitais. O autor afirma que, ao abrir a escola para o mundo e este para a escola, esse modelo de ensino projeta processos de comunicação mais planejados, organizados e formais, com outros mais abertos, como os que acontecem nas redes sociais, onde há um espontaneísmo na linguagem e uma maior possibilidade de pertencimento e imersão nas variadas formas de consumir e produzir informação e conhecimento.

Posto isso, considerando esses vastos meses de pandemia, em que a educação, por meio do modelo remoto, se configurou como uma forma paliativa de amenizar perdas no ensino, torna-se uma oportunidade valiosa para o contexto pós- pandêmico uma proposta que:

Concentre no ambiente virtual o que é informação básica e deixe para a sala de aula as atividades mais criativas e supervisionadas. É o que se chama de sala de aula invertida. A combinação de aprendizagem por desafios, problemas reais e jogos. A sala de aula invertida é importante para que os alunos aprendam fazendo, aprendam junto e também no seu próprio ritmo. (MORAN, 2015, p. 22). 
Nessa proposta, Moran (2015) sugere a inversão da lógica tradicional, onde o professor ensina antes na aula, e o aluno tenta aplicar, pesquisar ou praticar em casa o que aprendeu, para que, primeiramente, o aluno caminhe sozinho, com a mediação do professor, por meio de vídeos, leituras, atividades, e, depois, em sala de aula, desenvolva os conhecimentos que ainda precisam ser adquiridos, no contato com os colegas e com a orientação dos professores.

Seria, assim, uma forma explícita de desconstruir modelos bancários na educação viabilizando o fomento de estratégias que contemplem a participação e o estímulo criativo dos discentes na perspectiva de um ecossistema educacional sustentável. (FREIRE,1968).

Essa visão educacional, sob a ótica de um ecossistema sustentável, incide, sobretudo, na valorização e adaptação de ambientes que habilitem, apoiem e promovam atividades inovadoras e criativas (CAVALLO et al., 2016), tornando-se necessário, portanto, compartilhar pensamentos sobre a aprendizagem e promover, nos ambientes, condições favoráveis de estímulo ao aprendiz. Na natureza, a proliferação da espécie depende da adaptabilidade e de um terreno fértil ao seu desenvolvimento; de igual modo, é na educação.

Dessa forma, reflete a necessidade de repensar a educação por intermédio de modelos ecológicos, com vistas a fertilizar o terreno para a formação de sujeitos inovadores e criativos. Retoma-se, em vista disso, a visão otimista explicitada na finalidade deste artigo, ao pressupor o iminente cessar da pandemia. E propõe-se, de forma proativa, que as metodologias ativas sejam tidas como possibilidade de reconfiguração da proposta educacional. (CAVALLO et al., 2016).

Essas reflexões corroboram o pensamento de Schlemmer, Di Felice e Serra (2020), que afirmam que, quando as instituições educacionais, equipe diretiva, professores e estudantes se desafiam para a cultura digital, em rede, os mesmos se lançam ao imprevisível, ao novo, passam a usar diferentes TDs, apropriam-se, acoplam-se, agenciando-se com diferentes plataformas digitais, também em rede, e começam a problematizar o próprio conceito de aula e de sala de aula. Esse processo favorece a implementação de práticas, metodologias e a cocriação de pedagogias, possibilitando a reinvenção das instituições de ensino, em um contexto de realidade educativa cada vez mais "OnLIFE".

Sabe-se que a exclusão digital ainda é um fator que assombra a realidade brasileira, e que muitos alunos não dispõem de recursos tecnológicos para usufruir de iguais oportunidades no processo de ensino-aprendizagem, visto que esse tipo de exclusão também está ligado ao fator social. E, no que se refere a uma perspectiva de consumo das mídias, ainda que tenham acesso, muitos utilizam essa ferramenta de forma acrítica, resultando em desinformação e vulnerabilidade às Fake News. (MARCON, 2020).

Diante dessas disposições essenciais, torna-se relevante enfatizar que não se pretende colocar as metodologias ativas como resolução dos problemas educacionais, 
mas como um adubo na fertilização de ideias e propostas criativas, para pensar metodologicamente em ações que valorizem os saberes e a capacidade criativa do aluno, objetivando a atuação ativa na construção de sua aprendizagem.

\section{PERCURSO METODOLÓGICO}

Com vistas à compreensão da forma como as novas tecnologias têm auxiliado as ações pedagógicas no atual modelo de ensino, esta pesquisa se impulsionou pela necessidade de refletir acerca de quais são os limites e possibilidades na utilização das metodologias ativas, por intermédio ou não de TDs, enquanto proposta efetiva no desenvolvimento e construção de aprendizagem.

Enveredou-se, portanto, em uma pesquisa descritiva, qualitativa, de natureza aplicada, com caráter exploratório, que teve como procedimento as pesquisas de campo, documental e a bibliográfica, referenciada pelos estudos de Moran (2015); Ferrarine, Saheb e Torres (2019); Baseio, Santos e Carneiro (2021); Dias-Trindade e Moreira (2018).

A pesquisa descritiva é aquela em que o pesquisador apenas registra e descreve os fatos observados, sem interferir neles. Visa descrever as características de determinada população ou fenômeno, bem como a relação existente entre eles (PRODANOV; FREITAS, 2013).

Define-se a pesquisa aplicada à luz de Gil (2007 apud GERHADT; SILVEIRA, 2009), enquanto aquela que objetiva gerar conhecimentos para aplicação prática, dirigidos à solução de problemas específicos, envolvendo verdades e interesses locais.

Sobre a pesquisa de campo, entende-se, tal como Prodanov e Freitas (2013, p. 59), que esse tipo de procedimento consiste "na observação de fatos e fenômenos tal como ocorrem espontaneamente, na coleta de dados a eles referentes e no registro de variáveis que presumimos relevantes, para analisá-los".

Posto isso, no intuito de conduzir o caminho deste artigo para reflexões sobre as possibilidades de uso das TDs, vislumbrando os êxitos e/ou desafios encontrados no ERE, considerou-se, como ponto de partida, o local de fala dos professores. Sabe-se que são legítimas as limitações impostas à pesquisa de campo no atual cenário de isolamento social vivenciado. Porém, objetivando garantir o cumprimento dos protocolos de segurança contra a Covid-19, e, ao mesmo tempo, promover uma escuta sensível aos professores, de forma a garantir um retrato que melhor refletisse a realidade do ensino remoto em alguns municípios do estado do Maranhão, primou-se pela utilização de questionários elaborados e aplicados pelo formulário on-line na plataforma Google Forms.

Com base nos resultados dos questionários, foi possível constatar a participação de 13 (treze) professores das 3 (três) etapas da educação básica da rede pública do 
estado do Maranhão em efetivo exercício, nos municípios de Olinda Nova do Maranhão, Pedro do Rosário, São Luís e Timon. Vale enfatizar que se elegeu, como critério de escolha do lócus de pesquisa, o município no qual os pesquisadores desenvolvem suas atividades docentes, viabilizando um retrato mais fiel da realidade pesquisada e excluindo a necessidade de deslocamento, dada a circunstância de isolamento físico. Essa pluralidade de contextos permitiu à pesquisa um olhar mais amplo e diversificado sob diferentes cenários.

Para tratamento e interpretação dos dados coletados, optou-se pela análise do conteúdo, que, segundo Bardin (2011), é uma análise de significados que se ocupa de uma descrição objetiva, sistemática e qualitativa do conteúdo extraído das comunicações e suas respectivas interpretações.

Para tanto, iniciou-se com a etapa de pré - análise, em que o material foi organizado no intuito de compor o corpus da pesquisa na elaboração de indicadores que norteassem a interpretação final. Em seguida, realizou-se o processo de leitura flutuante, definido por Bardin (2011) como um contato inicial com os documentos, para a elaboração de explicações antecipadas do fenômeno observado.

Logo após, deu-se o processo de codificação dos dados, no qual se adotaram, como unidade de registro, os seguintes temas: Ensino Remoto, Metodologias Ativas e Tecnologias Digitais. Posteriormente, organizou-se o critério de categorização, buscando fazer aproximações e pontos de vistas semelhantes entre as falas dos pesquisados. Por último, na fase de interpretação dos dados, retomou-se ao referencial teórico procurando embasar e dialogar com a temática, dando sentido à discussão (BARDIN, 2011).

\section{RESULTADOS DA PESQUISA}

Os resultados obtidos puderam apontar que, dos 13 (treze) professores pesquisados, 9 (nove) eram do gênero feminino e 4 (quatro), do gênero masculino, e, em sua maioria, o tempo de serviço era acima de 10 (dez) anos. Com relação à formação para o exercício da profissão, constatou-se que $7,7 \%$ dos entrevistados têm formação no magistério, 53,8\% possuem nível superior e 38,5\% possuem especialização na área de formação. Percebeu-se representação dos sujeitos em variadas áreas de conhecimento, com maior prevalência na área de Linguagem $(30,76 \%)$, seguida de Pedagogia $(23 \%)$, professores que possuem mais de uma formação (23\%), Matemática $(7,6 \%)$, História $(7,6 \%)$ e Biologia $(7,6 \%)$. 


\subsection{Experiência Docente acerca dos êxitos e desafios encontrados no Ensino Remoto Emergencial - ERE}

Com a pandemia da Covid-19 desde 2020, sob orientações de decretos estaduais voltados à educação maranhense, as escolas que, outrora, funcionavam na modalidade presencial tiveram que adequar suas atividades ao ERE. Desse modo, novas práticas precisaram ser desenvolvidas e, com isso, muitos desafios e possibilidades, sobre as quais discutiremos nesta seção.

Nesse sentido, os docentes foram questionados no que se refere à utilização das TDs nas salas de aula em que atuavam, antes da pandemia. A maioria dos entrevistados não utilizava TDs nas aulas, antes do cenário pandêmico; outros, raramente, faziam uso, porém relatam o uso de alguns recursos de mídia, como datashow e retroprojetor.

Perguntou-se, ainda, sobre como os professores classificavam as suas habilidades na utilização de ferramentas digitais para o ERE. Na visão de Dias- Trindade e Moreira (2018), as competências digitais podem ser classificadas nos níveis A1 (recém-chegados) e A2 (exploradores). Enquadraram-se os entrevistados no nívelA1, uma vez que foram predominantes as habilidades básicas, ou seja, ainda em processo de aprendizagem e aprimoramento, o que evidenciou que a maioria dos docentes entrevistados precisa de mais tempo para experimentar essas ferramentas e para refletir sobre o seu uso adequado, rumo à fluência digital.

Ao ser analisada a percepção dos professores quanto às principais vantagens e/ ou desafios encontrados no modelo de ensino remoto posto em prática em sua respectiva escola, de modo geral, foi relatado que, embora com as dificuldades impostas pela pandemia, um ponto positivo observado diante do atual cenário foi a viabilização do ERE por meio da utilização das TDs, que, a partir de seu ecossistema e ambientes virtuais, têm possibilitado a continuidade dos processos educativos para os alunos.

Percebeu-se, no entanto, que grande parte dos docentes se sente apreensivo devido à falta de experiência e acaba fazendo o uso, por vezes inadequado, de recursos digitais para o perfil atual de ERE, o que determina uma ineficiência na prática pedagógica, visto que muitos professores apresentam dificuldade em integrar as TICs ao currículo e, consequentemente, durante o percurso da aprendizagem. (PERIN; FREITAS; CEBRIÁNROBLES, 2019).

Outra questão levantada pelos professores, como sendo um ponto negativo na perspectiva do ERE, é a limitação de acesso a uma rede de conexão de qualidade, além da ausência de outros recursos tecnológicos, senão somente o uso de aparelhos celulares, o que configura também a mesma barreira encontrada pelos educandos. Esse fator, nitidamente, reflete a necessidade de políticas públicas que fomentem e favoreçam o processo de inclusão digital. 
Nesse contexto, é oportuno afirmar que os desafios docentes atuais estão relacionados de maneira expressiva ao uso adequado das tecnologias digitais em prol de um processo de aprendizagem que vislumbre uma ação docente eficiente (DIAS-TRINDADE; MOREIRA, 2018), e isto também está atrelado ao processo de reflexão e autoavaliação do professor sobre sua prática cotidiana.

Cabe enfatizar que o cenário desafiador, de dúvidas e inseguranças frente ao uso das TDs no contexto do ensino remoto, se dá pela falta de letramento digital, fator que poderia ter sido suavizado durante a formação inicial docente. Contudo, conforme constatado, apenas três professores tiveram a oportunidade de cursar alguma disciplina na graduação, voltada para o uso das TDs na educação.

Vale destacar que alguns professores entrevistados participaram de formações promovidas pela Secretaria Municipal de Educação do Estado, cujo objetivo é a orientação acerca do uso de algumas ferramentas digitais para o contexto educacional.

Porém, conforme visto em Coutinho (2011), as mesmas não contemplaram o enriquecimento de possibilidades de construção de conhecimentos atrelado à proposta curricular. Apesar das dificuldades, os professores pontuam estar utilizando algumas TDs, plataformas e/ou aplicativos na mediação de suas aulas durante o período pandêmico, entre os quais, se destacam o celular, o Google Meet, o YouTube e a Plataforma EducaWeb. No entanto, a maioria dos professores destaca que: infelizmente, só utilizo o WhatsApp, trabalho em um município onde a maioria dos alunos não possuem Internet em casa e nem mesmo celular. Muitas vezes, a única maneira é a utilização de material impresso, então isso dificulta a utilização de outras plataformas digitais. (COUTINHO, 2011, grifo nosso).

Conforme destacado nas diversas seções deste artigo, a exclusão digital tem sido um dos maiores desafios ao acesso à educação neste atual contexto. Os professores, com suas dificuldades de letramento digital, acrescido do acesso restrito (ou inexistente) a redes e recursos tecnológicos pelos alunos, têm limitado a capacidade criativa e restringido as possibilidades de construção de conhecimento no cenário de ERE.

Para Marcon (2020, p. 100) acrescenta que: "Os 99\% da população que fez uso da internet no ano de 2019 utilizou por meio de telefone celular, e que há uma diferença profunda e marcante de acesso de acordo com a classe social", ressaltando que as exclusões social e digital estão intimamente interligadas, o que dificulta inovar a educação utilizando as TDs. Esses fatores conduzem preocupações pertinentes sobre a reflexão de como será a volta ao ensino para a modalidade presencial, visto o longo período de exploração fragmentada e fragilizada das possibilidades educativas.

Nessa perspectiva, um dos professores acredita que as novas TDs ainda não poderão potencializar o processo de ensinar, inclusive, após o retorno das aulas presenciais, pois a realidade educacional, na qual ela, especificamente, está inserida, é de 
enorme vulnerabilidade social e restrição tecnológica. Não obstante a isso, a maioria dos professores entrevistados pontuou que:

"Sim! A tecnologia sempre foi uma ótima ferramenta de apoio à educação. A diferença é que muitos profissionais não utilizavam ou nunca tinham se dedicado a oferecer aos seus alunos algo novo, novas metodologias. Eu sempre usei, mesmo antes da pandemia, agora só aumentou a frequência e a forma". (Entrevistado 1)

"Sim! Na minha opinião, a escola deve investir em aprendizagens virtuais aliadas aos presenciais, pois estamos na era digital, e é necessário se inovar, tornando o ensino dinâmico e eficiente". (Entrevistado 2).

"Sim! Se usadas a contento, e se os profissionais tiverem formações. As tecnologias são falas que destacam a importância das TDs na educação inseridas em contexto da cibercultura, seja nas aulas presenciais ou remotas. As tecnologias digitais trazem um leque de possibilidades enriquecedoras para o processo ensino aprendizagem". (Entrevistado 3).

No entanto, conforme destacado por Dias Trindade e Moreira (2018), apenas o uso dessas tecnologias não é suficiente para possibilitar uma educação inovadora. É necessário que os professores desenvolvam e/ou aprimorem competências digitais necessárias para utilizá-las significativamente, nas suas práticas didático-pedagógicas, superando o paradigma do uso meramente instrumental, possibilitando, tal qual destaca um dos professores, uma educação cada vez mais blended, misturada, híbrida, que vai além dos espaços físicos, explorando também os digitais (MORAN, 2015).

Ao se propor usar as TDs no processo de ensino-aprendizagem, é imprescindível que possibilitem práticas inovadoras, pois essas "[...] dão ênfase ao papel de protagonista do aluno, ao seu envolvimento direto, participativo e reflexivo em todas as etapas do processo educativo." (MORAN, 2018, p. 4 apud FERRARINI; SAHEB; TORRES, 2019, p. 4).

Nesse sentido, os professores compreendem o que são e a importância de metodologias ativas, como destaca:

\begin{abstract}
"De forma rasteira, acredito que metodologias ativas são processos em que o aluno é responsável pela aquisição de conhecimento, tornando o aluno protagonista do próprio desenvolvimento. Sempre usei a metodologia da sala de aula invertida, com objetivo de que os alunos chegassem à sala de aula com alguma bagagem sobre o assunto a ser abordado. Faço sempre indicações de sites, outros meios de pesquisa e a relação do que vai ser aprendido com a nossa realidade, sempre destacando qual a importância de se aprender esse conceito". (Entrevistado 1, grifo nosso).
\end{abstract}

Dessarte, no contexto de ensino imerso na cibercultura, onde as TDs, não obstante à exclusão "sóciodigital", representam possibilidades potencializadoras do conhecimento, existem evidências da necessidade de o professor apresentar-se como um mediador no processo de ensino-aprendizagem no qual, conforme Massetto (2000), o aluno possa assumir a posição de sujeito ativo, crítico e protagonista. 
Destaca-se, portanto, ao que preconiza Knuppel e Horst (2021) sobre a aprendizagem ativa, posto que esta deve se relacionar às diversas formas de trabalho educativo em que se busque a aprendizagem colaborativa com os outros e com o docente. Espaços em que, por meio da interação e da mediação do professor, criem-se oportunidades para que os alunos resolvam de forma autônoma situações problemas que Ihes sejam propostas.

\section{CONSIDERAÇÕES FINAIS}

O contexto de isolamento revolucionou a postura social frente a utilização de aparelhos tecnológicos, principalmente, os celulares. Em outros momentos, não se via com bons olhos a relação entre escola e essas tecnologias móveis. Alunos chegavam e eram punidos por portá-las em sala de aula. No entanto, hoje, conforme os relatos analisados, os celulares têm sido grandes aliados nesta trajetória de ERE.

Pode-se concluir que as angústias aparecem, sobretudo, pela questão social, na medida em que muitos alunos não têm acesso a qualquer tipo de equipamento móvel para acompanhamento das aulas. Por outro lado, foi visível, ainda, o despreparo docente no que tange ao atendimento das exigências deste contexto tecnológico digital. Alguns professores não tinham formações, e outros, ainda que tivessem, não contemplavam as suas reais necessidades.

Posto isso, a hipótese de migração de práticas tradicionais para o ambiente virtual foi confirmada, uma vez que a limitação de acesso às redes, a falta de formação de qualidade e a cristalização de paradigmas tradicionais de ensino foram levantados enquanto fatores restritivos da proposta de um ensino de qualidade em rede.

Considerando uma perspectiva esperançosa, foi possível verificar que alguns professores conhecem e já utilizam as metodologias ativas em sua prática. Desse modo, e diante de ações pautadas nessa linha, motivam e valorizam os conhecimentos dos alunos; a proposta de metodologias ativas explanada no escopo deste artigo foi corroborada, enquanto perspectiva de construção, que valoriza a aprendizagem e estimula o protagonismo discente nesse processo inovador de fazer educação.

Em suma, resgatando a visão analógica do ecossistema educacional, é notório que a pandemia tem fragilizado o solo do desenvolvimento escolar de muitos, em especial, daqueles com maior vulnerabilidade social. Porém se acredita que práticas docentes intencionalmente planejadas, pautadas em metodologia inovadora, que valorize e estimule as diversas formas de atuar sobre seu conhecimento, poderão sim ser um adubo importante no fortalecimento e enriquecimento dos processos de construção significativa de aprendizagem. 


\section{REFERÊNCIAS}

BASEIO, M. A. F.; SANTOS, P. V.; CARNEIRO, W. Educação e inovação: o uso de tecnologias em contexto pandêmico. Revista Uniítalo em pesquisa. São Paulo, v. 11, n. 1, 2021. Disponível em: http://pesquisa.italo.com.br/index.php?journal= uniitalo\&page=article\&op=view\&path\%5B\%5D=440. Acesso em: 10 jan. 2021.

\section{BARDIN, L. Análise de conteúdo. São Paulo: Edições 70, 2011.}

BEHAR, Patrícia Alejandra. O Ensino Remoto Emergencial e a Educação a Distância. Rio Grande do Sul: UFRGS, 2020. Disponível em: https://www.ufrgs.

br/coronavirus/base/artigo-o-ensino-remoto-emergencial-e-a-educacao-a-distancia/. Acesso em: 10 jan. 2021.

BRASIL. Ministério da Educação. Gabinete do Ministro. Portaria n. 343, de 17 de março de 2020. Dispõe sobre a substituição das aulas presenciais por aulas em meios digitais enquanto durar a situação de pandemia do Novo Coronavírus - COVID-19. Diário Oficial [da] República Federativa do Brasil: seção 1, Brasília, v. 53, p. 39, 18 mar. 2020. Disponível em: https://www.in.gov.br/en/web/dou/-/portaria-n-343-de-17-de-marcode-2020-248564376. Acesso em: 10 jan. 2021.

BRASIL. Ministério da Educação. Parecer CNE/CP n. 5, de 11 de março de 2020. Reorganização do Calendário Escolar e da possibilidade de cômputo de atividades não presenciais para fins de cumprimento da carga horária mínima anual, em razão da Pandemia da COVID-19. Brasília: Conselho Nacional de Educação, 2020c. Disponível em: http://portal.mec.gov.br/index.php?option=com docman\&view=download\&alias=145011-pcp005-20\&category_slug=marco-2020-pdf\&Itemid=30192. Acesso em: 10 jan. 2021.

CAVALLO, David et al. Inovação e criatividade na educação básica: dos conceitos ao ecossistema. Revista Brasileira de Informática na Educação, São Paulo, v. 24, n. 2, p. 143, 2016.

COMPETÊNCIA. In: DICIO, Dicionário Online de Português. Porto: 7Graus, 2020. Disponível em: https://www.dicio.com.br/inclusão/\&gt;. Acesso em: 27 abr. 2021.

CORONA VÍRUS-COVID-19. Ministério da Saúde. Disponível em: https://coronavirus. saude.gov.br/sobre-a-doenca. Acesso em: 25 de janeiro de 2021.

COUTINHO, Clara Pereira. TPACK: em busca de um referencial teórico para a formação de professores em tecnologia educativa. Revista Paidéia: Unimes Virtual, São Paulo, v. 2, n. 4, jul., 2011. Disponível em: http://revistapaideia.unimesvirtual. com.br. Acesso em: 10 jan. 2021. 
DIAS-TRINDADE, Sara; MOREIRA, José António. Avaliação das competências e fluência digitais de professores no ensino público médio e fundamental em Portugal. Revista Diálogo Educacional, Curitiba, v. 18, n. 58, p. 624-644, jul./set.,2018. Disponível em: https://periodicos.pucpr.br/index.php/dialogoeducacional/article/ view/24187. Acesso em: 30 abr. 2021.

DIAS-TRINDADE, Sara; SANTOS, Eniel do Espírito. Competências digitais de docentes universitários em tempos de pandemia: análise da autoavaliação digcompedu. Revista Práxis Educacional, São Paulo, v.17, n. 45, p. 1-17, abr.jun. 2021. Disponível em: https://periodicos2.uesb.br/index.php/praxis/article/view/8336. Acesso em: 30 abr. 2021.

FERRARINI, Rosilei; SAHEB, Daniele; TORRES, Patricia Lupion. Metodologias ativas e tecnologias digitais. Revista Educação em Questão, São Paulo, v. 57, n. 52, 2019.

FIGUEIREDO, A. D. Por uma escola com futuro: para além do digital. Nova Ágora, São Paulo, v. 5, p.19-21, 2016.

FREIRE, Paulo. Pedagogia do oprimido. 17. ed. Rio de Janeiro: Paz e Terra, 1968.

GIL, A. C. Como elaborar projetos de pesquisa. 4. ed. São Paulo: Atlas, 2007.

GOEDERT, Lidiane; ARNDT, Klalter Bez Fontana. Mediação pedagógica e educação mediada por tecnologias digitais em tempos de pandemia. Criar Educação, Criciúma, v. 9, n. 2, 2020.

HORN, Michael B.; STAKER, Heather; CHRISTENSEN, Clayton. Blended: usando a inovação disruptiva para aprimorar a educação. Porto Alegre: Penso Editora, 2015.

KNUPPEL. Maria Aparecida Crissi; HORST, Scheyla Joanne. A Educação Superior do presente e do futuro: um estudo das tendências a partir do Horizon Report (2019-2020). In: SERRA, Ilka Márcia Ribeiro de Souza, KNUPPEL. Maria Aparecida Crissi; HORST, Scheyla Joanne. (org.). Docência no ensino superior em tempos fluidos. São Luís: UemaNet, 2021. $283 \mathrm{f}$.

MARCON, Karina. Inclusão e exclusão digital em contextos de pandemia: que educação estamos praticando e para quem? Criar Educação, Criciúma, v. 9, n. 2, Edição Especial, 2020. Disponível em: http://periodicos.unesc.net/criaredu/ article/view/6047. Acesso em: 4 maio. 2021.

MASETTO, M.T. (org.). Docência na universidade. Campinas: Papirus, 2014.

MASETTO, M.T.; MORAN, J. M.; BEHRENS, M. A. Novas tecnologias e mediação pedagógica. Campinas: Papirus, 2000. 
MORAN, José. Metodologias ativas para uma aprendizagem mais profunda. Metodologias ativas para uma educação inovadora: uma abordagem teórico-prática. Porto Alegre: Penso, 2018. p. 2-25.

MORAN, José. Mudando a educação com metodologias ativas. Coleção mídias contemporâneas. Convergências midiáticas, educação e cidadania: aproximações jovens, São Paulo, v. 2, n. 1, p. 15-33, 2015.

MOREIRA, J. A. M; HENRIQUES, S; BARROS, D. Transitando de um ensino remoto emergencial para uma educação digital em rede, em tempos de pandemia. Dialogia, São Paulo, n. 34, p. 351-364, jan./abr. 2020. Disponível em: https://doi.org/10.5585/ Dialogia.N34.17123. Acesso em: 12 dez. 2021.

MOREIRA, José António; SCHLEMMER, Eliane. Por um novo conceito e paradigma de educação digital onlife. Revista UFG, Goiás, v. 20, 2020. Disponível em: https://www. revistas.ufg.br/revistaufg/article/view/63438. Acesso em: 12 dez. 2021.

PERRENOUD, Philippe; MAGNE, B. C. Construir: as competências desde a escola. Porto Alegre: Artmed, 1999.

PERIN, Eloni dos Santos; FREITAS, Maria do Carmo Duarte; CEBRIÁN-ROBLES, Violeta. Competências digitais de docentes da educação básica. Revista de Educação, Ciência e Tecnologia, São Paulo, v. 8, n. 2, 2019. Disponível em: https://periodicos.ifrs.edu.br/ index.php/tear/article/view/3596. Acesso em: 12 dez. 2021.

PRODANOV, Cleber Cristiano; FREITAS, Ernani Cesar de. Metodologia do trabalho científico: métodos e técnicas da pesquisa e do trabalho acadêmico. 2. ed. São Paulo: Editora Feevale, 2013.

SILVA, K. K. A.; BEHAR, P. A. Alunos da EAD on-line do Brasil e competências digitais. Revista EDaPECI, São Paulo, v. 19, n. 2, 2019

SCHLEICHER, A. Desafios para PISA. Relieve, França, v. 22, n. 1, 2016. Disponível em: http://go.uv.es/rY6ogph. Acesso em: 18 abr. 2020.

SCHLEMMER, E.; DI FELICE, M.; SERRA, I. M. R. S. Educação OnLIFE: a dimensão ecológica das arquiteturas digitais de aprendizagem. Educar em Revista. Curitiba, v. 36, n. 10, 2020.

TANGUY, Lucie. Racionalização pedagógica e legitimidade política. In: ROPÉ, Françoise; TANGUY, Lucie (org.). Saberes e competências: o uso de tais noções na escola e na empresa. 5. ed. Campinas: Papirus, 1997. p. 15-67.

Recebido em 23 de setembro de 2021 Aprovado em 17 de novembro de 2021 